\title{
A survey of flexible trainees in psychiatry in the North and South Thames Region
}

\author{
Joe Herzberg and llfra Goldberg
}

\begin{abstract}
Aims and method To review the experience, examination success and career progress of trainees on the flexible scheme in psychiatry in the North and South Thames region. Trainees in psychiatry who enrolled on the flexible training scheme 1993-1997 were included in the retrospective survey of flexible training records.

Recults Trainees on the flexible training scheme had gained experience in a broad range of posts before entering psychiatry for a mean time of 14 months. Fortynine per cent entered flexible training during basic specialist training and $41 \%$ during higher specialist training. This cohort of trainees performed better in the MRCPsych examinations than the national average. Forty-nine per cent of the trainees intended to become child and adolescent psychiatrists. Flexible trainees' progress to consultant status was slower. Implications the flexible training scheme attracts trainees of comparable quality to full-time trainees and encourages their retention in the workforce.
\end{abstract}

Flexible training opportunities are available to doctors in training who have a well-founded individual reason for wishing to continue training on a less than full-time basis. The trainee must be comparable in calibre to full-time trainees and the training programme they undertake must have educational approval from the Royal College of Psychiatrists and differ only from the training programme of those working full-time in that it will take proportionately longer to complete. These flexible training opportunities are usually arranged on a supernumerary basis, although job-sharing is also possible (Goldberg, 1997; Goldberg \& Paice, 1997).

In the Thames regions in 1998 there were 701 funded senior house officer posts and 309 funded specialist registrar posts. Thirteen senior house officers and 157 specialist registrars in psychiatry were in flexdble training programmes. Thus, $17 \%$ of all psychiatric trainees are training flexibly. They are supported in their posts with advice and guidance from the associate dean for flexdble training and, more recently have had further advice from within the speciality from the associate deans for mental health and lead consultants in the speciality. Some of them meet together regularly and frequently and, additionally, arrangements are made for them to meet together with flexible trainees from other specialities on an annual basis. Total numbers in flexible training in the Thames regions in all specialities and all grades have risen from 50 in April 1993 to 344 in 1998.

Psychiatry is a popular speciality for flexdble training and has been supported by a facilitating attitude from the Royal College of Psychiatrists. We wished to explore the career progression and outcomes for flexdble trainees. Two hypotheses were generated:

(a) Doctors training flexibly bring significant medical experience to their training.

(b) Doctors training flexdbly have comparable success rates in the MRCPsych examinations to all trainees.

\section{The survey}

The flexdble training office of North and South Thames maintains training fles on all doctors who enter flexdble training in all medical specialities. We examined the files of trainees who were in the flexdble training scheme in psychiatry at any time between April 1993 and April 1997. Trainees who had applied for flexdble training but had not yet been formally accepted on to the scheme were not included in the survey. In all, 67 flexible trainees in psychiatry met the inclusion criteria. Numbers and percentages relate to those trainees on whom the item of information was available from the training records and curricula vitae.

\section{Findings}

Subjects

Women made up $65 / 67$ (97\%) of the flexdble trainees studied. The reason for trainees wishing 
to train flexdbly were given in all 67 cases. This was child care in $60(90 \%)$ and personal health problems in two $(3 \%)$ cases. Five $(7 \%)$ gave a variety of other reasons including undertaking theological training and undergoing treatment for infertility.

\section{Experience before entering psychiatry}

Of the $57(85 \%)$ for whom the information was available, $56(98 \%)$ had completed their preregistration house officer training on a full-time basis. Only $12 / 53(23 \%)$ of flexible trainees had entered psychiatry straight after their preregistration house officer year. The time that flextble trainees spent in specialities other than psychiatry ranged from 0-75 months (mean 14 months). Sixteen (13\%) had worked in one speciality and $10(19 \%)$ had worked in two other specialities. Fifteen $(28 \%)$ received experience in between three and six specialities.

In 54 cases $(80 \%)$ it was possible to compute the number of months spent in full-time psychiatry prior to flexible training. The mean was 37 months. Fifteen trainees $(24 \%)$ commenced flexible training in psychiatry at senior house officer level; 22 (35\%) commenced at registrar level. Both these categories equate to general professional training. Twenty-six trainees (41\%) commenced training at senior registrar or specialist registrar level, that is, higher professional training. Many trainees entered flexible training when they passed Part II of the membership examination. Thirty-seven (55\%) had indicated a definite career choice within psychiatry on entering the flexdble training scheme. Eighteen trainees $(49 \%)$ indicated child and adolescent psychiatry, nine (24\%) old age psychiatry, seven (19\%) general psychiatry, two (5\%) psychotherapy and one $(3 \%)$ forensic psychiatry.

\section{Examination results}

We calculated the whole time equivalent training time to the successful passing of the Part I and Part II examinations for trainees where such calculations were possible from the information provided in the curricula vitae. In terms of Part I, sufficient data were available in 26 cases (39\%). The whole time equivalent to examination success ranged from 13 to 42 months (mean 18 months). Twenty (77\%) passed their Part I at the first attempt, four (15\%) at the second attempt and two $(8 \%)$ at the third or fourth attempts. Similar calculations were carried out on 42 cases $(63 \%)$ in respect of the Part II examination. The whole time equivalent range for passing this examination was 30-63 months (mean 40 months). Twenty-nine (69\%) appeared to have passed the examination between 30 and 42 months which equates to a first attempt at the
Part II examination, eight (19\%) had passed the Part II between 44 and 48 months, equating to a second attempt, and five (12\%) had passed Part II between 49 and 68 months which equates to three or more attempts.

Most trainees in this study remained on the scheme at the end point of the survey. However, trainees had joined the flexible training scheme at various grades and in 13 cases $(19 \%)$ it was possible to identify the grade which they entered after flexible training. Overall, three (23\%) became consultants, five $(39 \%)$ became senior registrars/ specialist registrars, two (15\%) became registrars, two (15\%) resumed training at senior house officer level and one (8\%) became a Wellcome Research Fellow. Contact information is available on 12 of the cohort who left the flexible training scheme during the period covered by this study. Following flexdble training $5 / 12(42 \%)$ obtained work on a full-time basis and seven $(58 \%)$ on a part-time basis.

\section{Discussion}

Reviews of the career histories of flexible trainees in our regions indicate that over three-quarters of the trainees have had experience in other medical specialities before choosing psychiatry and approximately half have had experience of 2-6 specialities. Doctors who train flexibly in psychiatry bring significant medical experience with them to their training. The first hypothesis was proven.

Trainees who had had some flexdble experience performed at least as well in the MRCPsych Part I and Part II Examinations as the national average, when their results were compared with those released periodically by the Royal College of Psychiatrists, where the overall success rate in each examination, at each occasion is approximately $50 \%$. The second hypothesis was also proven. At the present time, there are nearly 400 vacant consultant posts in England and full time trainees who achieve their Certificate of Completion of Specialist Training are able to move quickly into posts.

The advantage of the scheme as currently constituted is its flexdbility in allowing medical training to continue in circumstances in which trainees might otherwise be lost from the workforce. This is particularly important in psychiatry where there are major problems in filling consultant posts coupled with its high percentage of women entrants, who may require flexdble training for family reasons as these results indicate. There are major challenges which the flexdble training scheme faces. The success of the scheme has led to an increased demand for flexdble training and it is apparent that in the future, this increased demand can only be met 
financially by ensuring that for part of the flexible training period, trainees will work in job share arrangements, rather than entirely in supernumerary posts as previously. Programme directors and postgraduate deans will need to work closely to ensure that trainees continue to have posts which suit their training needs, in geographically convenient areas, while also ensuring that the demand for flexible training places is met for all trainees with well founded reasons for wishing to train flexibly.

\section{Acknowledgements}

We are grateful to Dr Elisabeth Paice, Dean/ Director - North Thames and Dr Brendan Hicks, Dean/Director - South Thames, for their helpful comments on this study.

\section{References}

GOLDBERG, I. (1997) Flexdble training in psychiatry. Psychiatric Bulletin, 21, 387-388.

- \& PAICE, E. (1997) New approaches to job sharing of training posts in the North Thames Region. British Journal of Hospital Medicine, 88, 193-196.

* Joe Herzberg, Associate Dean of Postgraduate Medicine (Mental Health) - North Thames, and Ilfra Goldberg, Associate Dean of Postgraduate Medicine (Flexible Training) - North and South Thames, Thames Postgraduate Medical and Dental Education (University of London), 33 Millman Street, London WC1N 3EJ

*Correspondence

\section{How to Teach Critical Review Skills}

\section{4 - 5 November, 1999, Weetwood Hall, Leeds}

This course will equip psychiatrists of all grades with the knowledge, understanding and skills to undertake critical appraisal of the published literature. It will also refresh knowledge and develop skills and attitudes necessary for teaching critical review for the MRCPsych Part II critical review paper. The course will be especially valuable for those wishing to acquire or refresh critical appraisal skills for life long learning, clinical psychiatric practice and for assessing evidence-based material.

\section{Topics covered}

- Does the design answer the research question?

- $\quad$ Sampling and setting

- Are the measures good enough?

- The use of statistics to assess the truth of main findings

- How to review a review

\section{CPD Validation Units 9}

Cost: $£ 180$ (inclusive of $B \& B$ accommodation, three course dinner, 2 course carvery lunch, tea and coffee during the course).

For an application form please contact: Mr Noel Bell, Royal College of Psychiatrists, 17 Belgrave Square, London, SW1X 8PG, Tel: 01712352351 ext 157 email: nbell@rcpsych.ac.uk 